\title{
"Los dueños de Chile somos nosotros": retrato de la élite en Los Millonarios, de Teatro La María
}

Article

Published Version

Creative Commons: Attribution-Noncommercial-No Derivative Works 4.0

Open access

Gonzalez Ortiz, C. ORCID: https://orcid.org/0000-0002-14208756 (2022) "Los dueños de Chile somos nosotros": retrato de la élite en Los Millonarios, de Teatro La María. Literatura y linguistica (44). pp. 141-167. ISSN 0716-5811 doi: https://doi.org/10.29344/0717621X.44.3052 Available at https://centaur.reading.ac.uk/102440/

It is advisable to refer to the publisher's version if you intend to cite from the work. See Guidance on citing.

Published version at: http://ediciones.ucsh.cl/index.php/lyl/article/view/3052

Identification Number/DOI: https://doi.org/10.29344/0717621X.44.3052

<https://doi.org/10.29344/0717621X.44.3052>

Publisher: Universidad Catolica Silva Henriquez

All outputs in CentAUR are protected by Intellectual Property Rights law, including copyright law. Copyright and IPR is retained by the creators or other copyright holders. Terms and conditions for use of this material are defined in the End User Agreement.

www.reading.ac.uk/centaur 


\section{CentAUR}

Central Archive at the University of Reading

Reading's research outputs online 


\title{
"Los dueños de Chile somos nosotros": retrato de la élite en Los Millonarios, de Teatro La María*
}

\author{
“We own Chile: portraits of the elite in Teatro La María's Los \\ Millonarios"
}

Camila Ymay González Ortiz ${ }^{* *}$

\section{RESUMEN}

Este artículo desarrolla un análisis del montaje Los millonarios, de la compañía chilena La María. Escrita por Alexis Moreno y estrenada en Santiago en 2014 la obra trata sobre unos abogados millonarios, racistas y socios de una importante y poderosa firma, quienes deciden tomar la defensa de un ciudadano mapuche, acusado del asesinato de una pareja de empresarios agricultores en la zona del Wallmapu (territorio mapuche). El análisis se enfoca principalmente en las operaciones y el material dramatúrgicos utilizados por Alexis Moreno para dotar a los personajes oligarcas de una naturaleza abyecta y la utilización en escena de material de archivo como mecanismo de historización de la ficción. En medio de las demandas de la ciudadanía por una reforma al modelo neoliberal y el actual proceso constituyente derivado de estas, la elite chilena (entendida como un grupo minoritario con un alto capital económico, político y cultural) ha sido identificada y cuestionada en su rol de autora y protectora de este modelo. Este artículo sitúa a Los millonarios como caso estudio del repertorio teatral nacional que, en sintonía con los procesos de movilización social del Chile contemporáneo, busca visibilizar y desarticular las distintas dimensiones en que las elites operan en el país y, en último término, provocar en el espec-
Palabras clave: teatro chileno, estados naciones, oligarquía, pueblo mapuche.

Este artículo se inscribe en un proyecto de investigación mayor sobre teatro, política y ciudadanía en el Chile contemporáneo. Una versión preliminar de este texto fue presentada en el congreso de LASA 2019 en la ciudad de Boston, Estados Unidos.

** Chilena. Doctora en Estudios Culturales Latinoamericanos del King's College London. Académica de la Universidad de Reading. Reading, Reino Unido. c.y.gonzalezortiz@ reading.ac.uk 
tador una discusión acerca del carácter elitario y supresor de los fundamentos en los que se basa la identidad nacional.

\begin{abstract}
This article develops an analysis of the play Los Millonarios 2015 by Chilean company La María. Written by Alexis Moreno and premiered in 2015 in Santiago, the play tells the story of a group of lawyers, wealthy, racists and partners of a very important and powerful law firm, who decided to defend a Mapuche citizen accused of killing a couple of agricultural entrepreneurs in the Wallmapu zone. The analysis focuses mainly on the dramatic material, with particular interest in exploring the dramaturgical operations used by Alexis Moreno to endow the oligarch characters of an abject nature and the use of archive material as a mechanism to historicize the fiction. Throughout the citizenry's demands for deep reforms to the neoliberal model and the current constituent process derived from them, Chilean elite (understood as a minority group with a high economic, political and cultural capital) has been targeted and questioned regarding its role as author and gatekeeper of this model. Within this context, this article places Los millonarios as a case study of the last decade's theatre repertoire which, aligned with the social mobilization processes, aims to shed a light and disarticulate the different dimensions in which these elites operate, with the ultimate goal of provoking in the audience a discussion about the elitist nature of the foundations on which national identity is built on.
\end{abstract}

Keywords: Chilean theatre, nationestates, oligarchy, Mapuche. 


\section{Introducción}

"Dick el carnicero: Lo primero que debemos hacer es matar a todos los abogados".

HENRIQUe VI, PARTE II, ACTO IV, ESCENA II.

El estallido social iniciado en octubre de 2019 se instaló como un evento de escala nacional y proporciones sísmicas que gatilló una explosión de descontento público hacia el modelo neoliberal chileno y sus asociados - e históricos - niveles de desigualdad. Continuas protestas a lo largo del país mostraron una desafección de los ciudadanos por la clase política de todos los sectores y demandaron cambios estructurales en diferentes áreas esenciales como salud, sistema de pensiones, y educación. La convergencia de estas demandas sectoriales se materializó en la presión ciudadana por la realización de un plebiscito que aprobara la redacción de una nueva constitución. La actual, creada y aprobada durante la dictadura cívico-militar de Augusto Pinochet (1973-1990) ha funcionado como la matriz legal que ha sostenido las políticas de privatización extremas aprobadas durante el régimen de Pinochet y luego perfeccionadas por los gobiernos de la posdictadura. Al mismo tiempo, esta constitución ha operado como un enclave autoritario (Garretón 22) o candado legal, impidiendo la posibilidad de aprobar reformas profundas al modelo.

Sin embargo, el estallido social y el proceso constitucional que derivó de este no ocurrieron por generación espontánea, sino que se presentan como hitos de un proceso liderado por un entramado de actores y movimientos sociales que desde hace más de una década se han tomado el espacio público para exigir mejorías en la calidad de vida de los chilenos. Desde los estudiantes el 2006 y 2011, hasta los movimientos regionales en el norte, centro y sur del país, como también los movimientos indígenas y sus demandas históricas por autonomía, el factor común de estos movimientos ha sido el interés por problematizar la imagen de Chile como ejemplo de desarrollo económico y social de la región. Este contexto de agitación social ha encontrado eco y establecido un diálogo con los creadores teatrales chilenos, quienes a través de sus propias experimentaciones estéticas han canalizado el malestar general de la población hacia los problemas de inequidad, generando espacios alternativos de participación y reflexión política. 
El montaje Los millonarios (2014) de la compañía La María pertenece a este repertorio teatral en línea con la producción cultural de la última década, altamente influenciada por los movimientos sociales surgidos en el país y, por lo tanto, crítica de los efectos negativos que ha tenido el modelo neoliberal salvaje a nivel social, económico y cultural. Protagonizada por un grupo de abogados de una importante firma en Santiago, Los millonarios intercala en escena la ficción con material de archivo de distintas fuentes y periodos para construir un retrato de la oligarquía chilena y su rol fundacional y protector de la configuración económica, social, cultural y simbólica de Chile.

La primera parte de este artículo consiste en una breve contextualización del montaje como ejemplo de un repertorio de teatro y performance de la última década en Chile, el cual he denominado giro ciudadano (González, "Teatro chileno..." y "Theatre and Democracy..." 48; 185). Este será seguido del análisis de Los millonarios, el cual está dividido en tres aristas. La primera es una introducción al montaje, sus principales elementos escenográficos, y la presentación de las ideas fuerza culturales y políticas en que los protagonistas (los abogados) basan su visión de mundo y, por lo tanto, su marco éticomoral. La segunda arista contrasta estas ideas fuerza con el comportamiento en privado de los abogados, develando una representación escénica de la elite como un grupo social de naturaleza inherentemente abyecta. La tercera arista se enfoca en analizar cómo la inclusión de material de archivo en escena permite una operación de historización de la ficción, revelando así la existencia de una genealogía de poder elitario.

\section{Teatro chileno y política hoy: desde un pacto elitario hacia un giro ciudadano}

El proceso de despolitización de la sociedad Chile durante la dictadura y la perpetuación de enclaves autoritarios - como la ya mencionada constitución de 1980, o el sistema binominal - una vez llegada la democracia, tuvo lugar bajo lo que Alberto Mayol (2016) llama un pacto elitario:

Toda elite es un pacto de grupos dominantes mediante el cual dichas agrupaciones asumen posiciones específicas en el espacio de poder de la sociedad. Toda elite es, entonces y por extensión, un 
pacto elitario. Ese pacto configura un pequeño grupo que toma control de una importante masa de la población. (20)

Este pacto elitario, cuyos orígenes pueden ser identificados en el periodo colonial, fue reforzado durante la dictadura a través de la relación entre altos mandos militares, la oligarquía latifundista y los partidos políticos de derecha. Durante este periodo "el empresariado de intensiva acumulación de capital ocupa un lugar preponderante" (Mayol 22). Este pacto luego fue sellado durante la transición con la incorporación de miembros de la elite política de la centro izquierda pertenecientes a la Concertación de Partidos por la Democracia- a la elite creada en los 80. Con la llegada del nuevo milenio, el sentimiento de malestar hacia esta democracia incompleta (Garretón 22) y el pacto elitario se intensificó entre los ciudadanos, especialmente en las generaciones más jóvenes, las que comenzaron a subrayar las tensiones surgidas entre la imagen positiva de Chile en el exterior como una nación económicamente robusta y políticamente estable, versus los altos niveles de desigualdad, endeudamiento y falta de canales alternativos de participación política. Dentro de este contexto, el movimiento estudiantil de 2011, en sus demandas por eliminar la naturaleza mercantil del sistema de educación, fue evidente en su denuncia de un pacto elitario entre la clase política y la elite económica. Como describe el exlíder estudiantil y actual diputado Gabriel Boric:

La mayoría de los partidos recurrió a los empresarios para financiar sus campañas y se trasformaron en sus empleados ... el Parlamento chileno no representa la diversidad social, sino a una elite de Santiago, machista y, evidentemente, de clase alta. (El Mostrador párr. 4)

Es dentro de este contexto de despertar social en el país que surge el giro ciudadano. A nivel general, el giro ciudadano se instala como una inflexión temática y formal entre la producción de teatro y performance en Chile y su dimensión política. Enmarca la posición de creadores cuyos trabajos presentan una fuerte crítica hacia los procesos neoliberales de modernización efectuados durante la dictadura y luego perfeccionados por los gobiernos en democracia (González, “Theatre and Democracy..."). Mi uso del término "ciudadano" está asociado a cómo estos repertorios teatrales se han articulado y evolucionado en sintonía con el surgimiento de distintos movimientos sociales, como 
el ya mencionado movimiento estudiantil del 2011, la Revolución Pingüina en 2006, movimientos regionales e indígenas. Junto con La María, dentro de las compañías más representativas de este giro están: Bonobo, Colectivo Zoológico, La Re-sentida y Teatro Público; y dramaturgas y dramaturgos como Nona Fernández, Carla Zúñiga, Juan Pablo Troncoso, Guillermo Calderón, Luis Barrales, Camila Le-Bert y Gerardo Oettinger, entre otros. Si bien todos estos creadores pueden abarcar un variado conjunto de formatos, estilos y poéticas escénicas, es posible identificar un interés común por explorar la figura de la elite, su influencia y responsabilidad histórica en la configuración política, económica y cultural del país y, por lo tanto, en las diferentes esferas de poder en las que aún sigue operando. Es así que en este contexto sería más preciso hablar de las elites. A partir de lo anterior, en muchas de las obras representativas del giro ciudadano, una de sus principales características es que el sujeto a representar y el núcleo dramático transitan desde la representación de las víctimas de abusos a los derechos humanos, y/o personaje provenientes de sectores socialmente marginados (muy propio de las producciones teatrales de los 80 y 90 ) hacia un interés por explorar el mundo de los perpetradores/agentes del Estado autores de las violaciones, y miembros de las capas superiores de poder de la sociedad chilena. Es en este contexto sociopolítico y de producción cultural donde se inserta este análisis de Los millonarios, el cual se presenta como un montaje que busca problematizar los cimientos en que se funda y sostiene la República de Chile y, en particular, instalarse como una reacción a la naturaleza elitaria de estos cimientos, tanto en sus dimensiones económicas, políticas, sociales como epistemológicas.

\section{Los millonarios: "Yo soy lo que se necesita dependiendo de la ocasión"}

La María fue fundada en Santiago en 2000 por Alexandra von Hummel y Alexis Moreno, ambos estudiantes de la Escuela de Teatro de la Universidad de Chile ${ }^{1}$. Desde su fundación, la compañía ha estrenado 20

1 Aunque Moreno y von Hummel son los líderes fundadores de la compañía, esta en la actualidad cuenta con un núcleo creativo que incluye a los diseñadores Ricardo Romero (quién ha diseñado la iluminación de todos sus montajes) y Rodrigo Ruiz, y a los actores Tamara Acosta, Manuel Peña, Elvis Fuentes y Rodrigo Soto. 
montajes, los cuales abarcan desde textos originales escritos por Moreno hasta adaptaciones y versiones libres de clásicos universales (El pelícano [2002], Hamlet [2003], La gaviota [2004]) y chilenos (Topografía de un desnudo [2010]). A pesar de que la compañía ha producido un repertorio de extensa variedad, tanto en lo temático como en lo formal ${ }^{2}$, es posible identificar una serie de elementos que son referencias a la cultura pop de los $80^{3}$ (década en la que los integrantes de la compañía vivieron su infancia), humor negro, efectos especiales ${ }^{4}$, y actuaciones melodramáticas, desbordadas llegando a ser incluso esperpénticas. Para Fernanda Carvajal y Camila van Diest (2009) un elemento central y presente en prácticamente todos los montajes de la compañía hasta la fecha es la violencia en sus distintas configuraciones, tanto en los signos, lenguajes y temáticas como también en el estilo actoral (340). Al mismo tiempo, las autoras trazan una evolución de la compañía en su tratamiento de la violencia en escena, transitando desde una dimensión micropolítica - representada principalmente en el estilo actoral y propia de los primeros montajes- hacia una macropolítica:

En las propuestas que el grupo desarrollaría más adelante, la violencia atravesará hacia más dimensiones de la escena y de sus interpelaciones al espectador, abriéndose sus figuraciones desde las pequeñas historias familiares, hacia fragmentarios relatos colectivos que interrogan la historia nacional reciente. (309)

La obra Los millonarios, fue estrenada en Santiago de Chile en julio del 2015 en el Teatro de la Universidad Católica ${ }^{5}$ (Teatro UC). El mon-

2 Para un análisis detallado del repertorio de La María hasta 2008 ver Nomadismos y ensamblajes: compañías teatrales en Chile 1990-2008 de Fernanda Carvajal y Camila van Diest (2009).

3 Estas referencias pueden ir desde canciones, personajes de series de televisión, o sujetos pertenecientes a la cultura popular chilena, como por ejemplo la monga que es un personaje/monstruo en un juego del parque temático Fantasilandia ubicado en el Parque O'Higgins en Santiago.

4 Son efectos especiales que generalmente ocurren de manera breve e inesperada durante la obra, causando un punto de quiebre en la acción dramática. Esta estrategia se ha visto, por ejemplo, en la caída de la parrilla de luces (El pelícano), disparo en la cabeza de un personaje (Superhéroes), quiebre de un ventanal (La tercera obra), y sillas que se mueven sin que las toquen (Las huachas) entre otros.

$5 \quad$ Ficha artística: Dramaturgia y dirección: Alexis Moreno; elenco: Alexandra von Hummel, Elvis Fuentes, Manuel Peña, Rodrigo Soto, María Elena Valenzuela y Daniela Fernández; Diseño de iluminación: Ricardo Romero; Diseño de escenografía: Rodrigo Ruiz. 
taje se inserta dentro de una trilogía que incluye también las obras $E l$ hotel (2016) - cuyos protagonistas son viejos culpables de crímenes de lesa humanidad durante la dictadura (agentes, torturadores, soplones) quienes viven en un hotel en la Antártica- y Fe de ratas (2018) que se enfoca en sacerdotes de la iglesia católica acusados de abusos sexuales a menores. Los tres montajes sitúan en sus núcleos dramáticos a las distintas esferas de poder (económica, política y religiosa) del Chile contemporáneo y el estado de impunidad donde operan. La trilogía se instala entonces en sintonía con el interés de las obras pertenecientes al giro ciudadano por problematizar el pacto elitario, y con la lectura ofrecida por Carvajal y van Diest (2009) acerca de la evolución de La María en la última década por redirigir sus paradigmas dramatúrgicos y materialidades escénicas hacia la exploración de temáticas de carácter nacional y contingente.

La acción en Los millonarios tiene lugar en Santiago, en la casa de un abogado -identificado como $\# 2^{6}$ - racista, poderoso y millonario, quien con la ayuda de otros dos socios de la firma (\#1 y \#3) ${ }^{7}$ y un abogado asesor experto en crisis $(\# 4)^{8}$, pasarán toda la noche preparando la defensa del imputado mapuche Erwin Calluqueo, acusado de asesinar a un matrimonio de empresarios agricultores en el sur de Chile. La María tomó como inspiración el caso real Luchsinger-Mackay ocurrido en 2013, cuando el matrimonio de Vivianne Mackay y el empresario agricultor Werner Luchsinger murieron producto de un incendio provocado en su casa en el fundo de la familia en la IX Región. Hasta ahora el único imputado por el crimen es el Machi Celestino Córdova. En Los millonarios, los abogados demuestran un profundo desprecio por el pueblo mapuche con \# 1 declarando "yo no conozco algo más desagradable que tener que defender a un cholo de esos" (Moreno, "Los millonarios" 114). Sin embargo, deciden defender a Edwin Calluqueo como un acto de venganza ante los empresarios asesinados quienes habrían decidido hacer negocios con empresarios chinos, afectando directamente los intereses económicos de los abogados socios principales de la firma. Esta comedia negra acerca de unos abogados que deciden de-

$6 \quad$ Representado por el actor Elvis Fuentes.

7 Representados por los actores Manuel Peña y Alexandra von Hummel respectivamente.

8 Representado por el actor Rodrigo Soto. 
fender a alguien y algo en lo que no creen en lo absoluto responde, según el propio Alexis Moreno, "a un interés de la compañía por generar un relato desde la otra vereda, desde la radicalidad del discurso contrario al mapuche. Personas que digan autóctono y originario, o Araucanía y no Wallmapu. Y otras cosas peores" (Moreno, "¿Qué es la patria?" 148). A partir de lo anterior, Moreno articula un texto cuyo lenguaje es directo, denso en contenido legal y contexto histórico, y pornográfico en el racismo y clasismo expresado por los protagonistas hacia el sujeto y cultura indígena. Al mismo tiempo, el relato intersecta elementos característicos del repertorio dramatúrgico y performativo de La María como los ya mencionados: humor negro, actuaciones desbordadas, efectos especiales, y giros absurdos en la trama. La interacción de estos elementos es fundamental para la comprensión del lugar del habla elegido por la compañía para aproximarse al tema, con Moreno afirmando que "por supuesto que no nos interesaba un tratamiento amable ni paternalista de este; todo lo contrario, la insolencia y el descaro debían armar el discurso escénico de un texto que pretendía instalar discusión entre 'chiste y chiste' (Moreno, “ $¿ Q u e ́$ es la patria?”, 151). Hace sentido entonces que en Los millonarios estas coordenadas dramatúrgicas, visuales y actorales para representar a la elite chilena salgan a la luz desde el primer momento, en la descripción de los personajes:

1: Hombre, abogado experimentado, millonario.

2: Hombre, abogado con menor experiencia, millonario.

3: Mujer, abogada experimentada, fría, millonaria.

4: Hombre, abogado experto en crisis, millonario.

5. La empleada, maquillada, pobre. (Moreno, "Los millonarios" 110)

Los personajes son definidos exclusivamente en relación con su condición de género, profesión y clase social. Los abogados nunca se nombran, no son seres o personajes psicológicos, sino que estos se plantean, según Moreno, "como fuerzas representantes de lo abyecto ... y son pensamiento y estrategia constante” (Moreno, “¿Qué es la patria?" 148).

Dentro del contexto de este artículo entenderemos como miembros de la elite a quienes "tienen el máximo de lo que puede tenerse, que generalmente se considera que comprende el dinero, el poder y el prestigio, así como todos los modos de vida a que conducen esas co- 
sas" (Wright Mills 17). A partir de esta definición y una primera lectura del montaje, podemos identificar otros elementos escenográficos y características de los personajes que construyen este universo elitario. Los abogados durante toda la obra beben whiskey, escuchan música clásica (Chopin), son atendidos por una empleada doméstica, entrelazan la preparación del caso con anécdotas de banquetes y excesos con otros millonarios, y revelan que históricamente han acudido a la coima como método para ganar los casos. Además, su conocimiento respecto de la historia universal y manejo de conceptos complejos devela un acceso ilimitado al conocimiento y, por lo tanto, un alto capital cultural. La acción transcurre específicamente en la oficina de la casa de \#2, y desde un aspecto escenográfico la antigüedad y estilo clásico de los muebles y utilería (escritorio, sillas, vasos de cristal) también revela el contexto privilegiado en el que estos individuos viven. Todos estos elementos conjugan y develan lo que el público en general tendería a asociar como parte del gusto de clase alta. El gusto de los abogados y su capacidad de acceder a objetos a los que la gran mayoría no puede funciona aquí como orientador y demarcador social (Bourdieu 1977) que aísla a este grupo de las otras clases. En ese sentido, este espacio escénico más que develar un gusto burgués, articula una estética oligárquica en donde el capital simbólico de sus elementos de lujo cristaliza la posición de poder de estos individuos por sobre la mayoría. En contraste con esta estética oligárquica, las paredes del espacio están construidas con madera prensada, material hecho de partículas de madera y utilizado para la construcción de objetos y espacios de bajo costo. Esta decisión estética y paradojal - muebles de alta alcurnia en un espacio construido con material simple y precario- cumple un rol simbólico, histórico y político. La madera prensada es una referencia a la industria forestal, específicamente a empresas como la Celulosa Arauco y Constitución y la empresa CMPC $^{9}$, cuyos socios mayoritarios son el Grupo Angelini (de la famila Angelini) y el Grupo Matte (de la familia Matte $)^{10}$ respectivamente. Sus áreas de negocio incluyen el

9 También conocida como La Papelera.

10 El Grupo Angelini es un holding empresarial que también posee inversiones en áreas como combustible (COPEC), gas (Abastible, Metrogas), Pesca (Corpesca), transporte (Cruz del Sur), minería (Minera Isla Riesco), y agrícola (Valle Grande S.A); y con ingresos de US\$18.000 millones (Forbes, “AntarChile”). Similarmente, el Grupo Matte posee además un portafolio de inversiones en las áreas de telecomunicaciones (ENTEL), 
dominio y explotación de grandes áreas forestales en el sur de Chile. Durante la dictadura, la empresa forestal se vio beneficiada con tierras expropiadas a las comunidades indígenas a través del Decreto de Ley $701^{11}$ (Conaf). En Los millonarios, los abogados dan cuenta de que el matrimonio asesinado "era, prácticamente dueños de un tercio de la región junto a los Matte y los Angelini. Nuestra firma los representaba en una docena de negocios" (Moreno, "Los millonarios" 115). La escenografía de paredes de madera prensada, por lo tanto, se instala como un comentario visual y político respecto de la industria forestal y su rol histórico en la facilitación del capital económico que alimenta la interacción e interdependencia entre los distintos agentes miembros del entramado oligárquico.

La obra comienza con un epílogo entre \#1, \#2, \#3, en donde \#1 y \#3 recriminan a \#2 por haber elegido defender a Calluqueo. En esta primera escena se intercalan dos reflexiones/ideas fuerza complementarias donde se aprecian las cualidades de "pensamiento y estrategia constante" con que Moreno ha dotado a los abogados. La primera idea fuerza - expresada a lo largo de esta escena por el abogado \#1— señala la importancia de la flexibilidad que hay que tener de acuerdo con el contexto; la capacidad de adaptarse, y el sentido de supervivencia:

\#1: Yo, por ejemplo, no tengo empacho alguno en cagarme en la bandera si es necesario... o besarla y jurar morir por ella... ¿Y por eso soy un ser asqueroso? No, señor.

$[\ldots]$

\#1: Yo soy lo que se necesita dependiendo de la ocasión...

$[\ldots]$

\#1: Patria, país ciudadano, derechos, justicia... la justicia varía su definición dependiendo del contexto (Moreno, "Los millonarios" 110).

electricidad (Colbún), y bancaria (Banco BICE), e ingresos de US\$6.300 millones (Forbes, "Empresas CMPC").

11 El decreto de ley 701 (DL701) de 1974 es un cuerpo legal que impulsa el desarrollo forestal en Chile. Permite la bonificación para la forestación de suelos, y bonificación y beneficio tributario para la administración y manejo de bosques plantados para el desarrollo forestal (Conaf). 
Para \#1, la patria es una invención y una herramienta conceptual que ha sido utilizada por la elite para mantener la ilusión de unidad nacional y del status quo. Al mismo tiempo, los conceptos de ciudadano, derechos y justicia son despojados de su dimensión modernista, humanista, y emancipadora - dimensión fundamental para la misión independentista de los nuevos Estado-nación en América en el siglo XIX - para revelar su inherente dimensión mercantil. En el Chile neoliberal de los siglos XX y XXI estos conceptos y símbolos patrios funcionan como moneda de cambio y para \#1 son precisamente los abogados quienes cumplen el rol de ponerlos en valor de acuerdo "al contexto". Esta postura ética e ideológica pendular y neoliberal resuena con las ideas de Zygmunt Bauman (2007) y su sociedad líquida, en donde las estructuras de comportamientos, tendencias e instituciones y normas sociales en general "ya no pueden (ni se espera que) mantengan su forma por más tiempo, porque se descomponen y derriten más rápido que el tiempo que les toma solidificarse, y cuando son solidificada, poder asentarse"12 (1). Dentro del paradigma líquido, las ideologías que sustentan los comportamientos de grupos o individuos son volátiles y flexibles. En ese sentido, la permeabilidad ética de \#1 es comparable a los personajes de La imaginación de futuro (2013) de la compañía La re-sentida. La imaginación del futuro presenta al presidente Salvador Allende en su oficina en La Moneda el 11 de septiembre de 1973, ya acorralado por las Fuerzas Militares, y ensayando lo que será su discurso final a la nación. Sin embargo, Allende es asesorado por ministros cuyas apariencias y comportamiento político pertenecen a gobiernos de izquierda de la posdictadura, instalándose en escena una realidad multitemporal entre septiembre 1973 y 2013. He argumentado anteriormente que estos ministros también comparten cualidades líquidas, ya que por una parte su lealtad hacia Allende y al proyecto de la Unidad Popular va declinando a lo largo de la obra y, por otra, porque representan a las cúpulas de poder de la izquierda luego de 1990 como una clase política mutable, cuyos miembros han coqueteado tanto con ideologías socialistas como con las neoliberales (González, "Theatre and democracy..." 112).

12 "Can no longer (and are not expected) to keep their shape for long, because they decompose and melt faster than the time it takes to cast them, and once they are cast for them to set" (traducción propia). 
La segunda idea fuerza de la primera escena-prólogo es sostenida por \#3 y habla de la tendencia histórica de los grupos populares hacia la violencia:

\#3: Inventamos el orden porque como especie nuestra naturaleza es la de asesinar, somos depredadores y, si nos sueltan en un lugar, destruimos todo.

\section{[...]}

\#3: Te puedes demorar 500 años en construir el orden, pero algo sucede y en menos de un minuto se puede destruir. Y, el "pueblo" dime tú. El "pueblo" ... ¿Qué hace el pueblo sin orden? ¿Se roba televisores? ¿Viola?

\section{[...]}

\#3: La democracia es la peor forma de gobernar y generar orden porque la masa no es astuta. Es solo, una masa. (Moreno, "Los millonarios" 110).

De acuerdo con el discurso de \#3 el indígena es inherentemente salvaje, de modo que el territorio nacional comenzó su proceso de civilización y desarrollo solo desde y gracias a la llegada de los españoles. Al mismo tiempo, la dimensión racista presente en la dicotomía español/civilizado-indígena/salvaje, adquiere en la última cita una dimensión clasista con la dicotomía rearticulada en criollo oligarca/ civilizado-masa popular/salvaje.

En estas dos ideas fuerza acerca de la importancia de adaptarse según el contexto, y la tendencia de las masas a la autodestrucción, no solo se respira una actitud cínica, pesimista y condescendiente, sino que además ambas funcionan como una base moral y dramática constante durante toda la obra para representar y justificar la relación racista y clasista de los abogados hacia su defendido, la comunidad mapuche y la clase trabajadora chilena en general. Al mismo tiempo, estas ideas fuerza defendidas por los abogados en el prólogo serán tensionadas durante la obra producto de la información que los abogados irán revelando acerca de sus vidas como miembros de la elite, y a través del comportamiento de estos durante la noche gatillado por el alcohol, ya que tal como explicita la primera acotación del texto: "Es de noche. Siempre beberán... y el alcohol hará efecto" (Moreno, "Los millonarios" 110). 


\section{Señoritos en lo público, bestias en lo privado}

La representación de la oligarquía en Los millonarios como un grupo de seres abyectos, se materializa de manera evidente en la primera parte cuando \#3 describe las fiestas que el abogado fundador y jefe de la firma - y padre de \#2- solía organizar con la participación de otros miembros de la elite:

\#1: Lo obsceno de las fiestas era el correlato de los éxitos en la corte. Quizás se hacían para extirpar los resabios de culpa de algunos juicios. No lo sé... pero de tener dinero la firma comenzó a tener poder, y luego, a distribuir y decidir el poder.

\#3: La mejor de todas las celebraciones fue una donde teníamos que llegar vestidos como pordioseros, pero no de disfraz, sino hediondos, sucios, comprábamos la ropa de los vagabundos reales y así, sin lavarla ni nada nos las poníamos, evidentemente la ropa interior era nuestra ... por Dios, qué entretenidos, de deseos salvajes y perversiones insólitas, llegábamos como pordioseros. Todas las sillas, sillones, sofás eran retirados de lugar. Nos servían en bandejas de plata sobras para comer, mendrugos de pan. El vino de primera calidad, eso sí, y fíjate que las sobras daban un toque muy fino al paladar, vino servido en copas de cristal maravilloso, por lacayos con peluca y vestuarios de época. iAy! Llama a tu papá, me muero por escuchar su voz. (Moreno, "Los millonarios" 118)

El relato de \#3 nos presenta a una elite que en privado establece una relación obscena con su situación de privilegio dentro del contexto del Chile desigual. La falta de pudor y amoralidad se evidencia tanto en la anécdota en sí misma —-disfrazarse de alguien en situación de calle por placer- como en la forma en que esta es narrada por la abogada; desde un goce e incluso nostalgia por la experiencia de jugar a ser pobres por unas horas. En una primera instancia, la anécdota podría ser percibida como una exageración, un cuento inverosímil y en línea con los relatos absurdos propios de la dramaturgia de Alexis Moreno y el repertorio de La María. Sin embargo, si dirigimos la mirada por un momento hacia la historia y la contingencia nacional, y recordamos situaciones como la foto del presidente chileno Emiliano Figueroa (18661931) vestido de mendigo (Gumucio "Mendigos de utilería"), o la vez en que el actual presidente del país y multimillonario Sebastián Piñera en el 2007 se disfrazó de pobre para un programa de televisión y con 
una cámara oculta salió a caminar por ciudad, negándosele incluso el acceso a la sede del canal Chilevisión, de cual era dueño en ese tiempo (Publimetro, "Videos tuiteros..."). Desde esta óptica, entonces, el relato de \#3 se instalaría como una farsa, un simulacro de lo real donde la realidad no es inventada sino aumentada.

Más adelante en el relato, el comportamiento abyecto de los abogados se trasladará hacia La Empleada, quinto personaje, y definida en el listado de personajes como "maquillada y pobre". Aparece por primera vez en la escena titulada $\mathrm{Mudai}^{13}$. La mujer aparece vestida con su delantal/uniforme de trabajo, bien peinada y maquillada. Es una escena corta, pero cuya acción dramática opera simbólicamente en distintos niveles.

(Entra la empleada. En realidad ha estado hace un buen rato, quizás desde el principio pero nadie lo ha notado. Es una mujer blanca, rubia, de mirada severa)

\#2: Whisky.

La Empleada: ¿Alguna etiqueta especial?

(Todos la miran)

\#2: ¿Por qué habló?

La Empleada: Perdón, señor.

\#2: ¿Por qué habla?

La Empleada: Un error señor.

\#2: ¿Por qué sigue?

(La empleada guarda silencio)

Azul. Es una ocasión especial. Y algo para comer.

(La empleada se dispone a salir)

Otra cosa. Trabajaremos hasta tarde y no queremos tenerla por acá cerca. Puede irse.

No me gusta cómo se está maquillando... Retírese.

Otra cosa: ¿Usted sabe cómo se llama ese licor que toman los indios? Uno que es de maíz regurgitado o algo igual de asqueroso.

13 El Mudai (Del mapudungun Muday), es una bebida alcohólica hecha a partir de la fermentación del maíz o trigo. El Mudai es una bebida tradicional del pueblo Mapuche. 


\section{(La empleada se demora 15 segundos en responder.)}

La empleada: Mudai señor.

\#1: ¡Eso es! Mudai. Muchas gracias, señorita.

(\#1 se acerca a ella. Comenzará a acosarla hasta manosearla sin pudor. A nadie le interesa lo que sucede. La secuencia debe terminar en una grosera acción de coito). (Moreno, "Los millonarios" 119)

La escena funciona como un microcosmo representativo de los discursos racistas y clasistas que han fomentado acciones de dominación y control de la elite chilena sobre la clase trabajadora, y en particular sobre las empleadas domésticas. La asimetría presente en la relación de poder entre la empleada y los abogados se refleja, por ejemplo, en el tono humillante y coercitivo con el que \#2 se comunica con la trabajadora. El empleador controla qué es lo que ella puede hablar y cuándo hacerlo. Se devela también la siempre presente desconfianza del empleador sobre la trabajadora como un ser entrometido ("\#2: no queremos tenerla por acá cerca") o potencial ladrona. La relación asimétrica opera también desde una dimensión biopolítica (Foucault 298) representada en el poder total y coercitivo que ejercen los abogados sobre el cuerpo de la trabajadora, tanto en el plano estético (“\#2: No me gusta cómo se está maquillando"), como sexual (manoseo y acción de coito por parte de \#1). Aunque la trabajadora no se opone al abuso sexual de \#1, esta no es una transacción consentida, sino "aceptada" debido al miedo de la empleada de perder su trabajo. Al mismo tiempo, esta acción puede ser leída desde un marco histórico y geopolítico, ya que el cuerpo abusado psicológica y sexualmente por los abogados simboliza la colonización y dominación del territorio indígena por parte de los conquistadores españoles durante la Colonia, y luego perpetuado por una elite criolla (descendiente de los colonizadores) y una elite europea cuyo asentamiento en el territorio mapuche fue promovido y legitimado por el Estado de la nueva República de Chile.

Estas conductas salvajes e inmorales de los abogados se contraponen a la idea fuerza expresada por \#3 en la primera escena del montaje. Para la abogada, los incivilizados son las masas trabajadoras y los indígenas - violentas por naturaleza - que fueron civilizados por los conquistadores. El comportamiento grosero y violento de \#1, por lo tanto, desmantela esta cosmovisión (orden de las cosas) articulada por 
la elite, que los instala como un bastión de capital cultural, civilizado y de conducta intachable. El montaje, de forma contraria, dota a estos abogados con la capacidad de articular ideas, estrategias complejas y gran dominio de tecnicismos legales, pero que a puertas cerradas y en compañía de otros miembros de su tribu, serían sus instintos más animales e inmorales los que alimentan sus comportamientos. Este interés por explorar la disociación entre la percepción que tienen de sí mismos los cuatro abogados como miembros de una clase privilegiada y superior, versus la naturaleza racista e inmoral de sus discursos y comportamientos es llevada al límite cuando el personaje de La Empleada vuelve a ser llamada por los abogados para que les enseñe cómo pronunciar la palabra mapuche. En un giro inesperado y absurdo vemos que entra a escena una actriz distinta interpretando el personaje ${ }^{14}$. Sin embargo, para los abogados sigue siendo el mismo personaje, solo que esta vez vendría sin maquillaje. La nueva actriz es de estatura mas baja y de piel morena y entra a escena haciendo la acción de desmaquillarse. Los abogados reaccionan con pavor:

\#3: ¡Nos invaden! ¡Nos van a quemar!

\#1: ¡Un monstruo!! ¡iAuxilio, bomberos!! Llegaron, nos van a matar...

\#4: Yo no quería venir, por favor no me comas...

\#2: ¡iPero ¿qué significa esto?!! ¿Por qué mierda entra sin maquillaje?

La Empleada: Perdón, señor, es que me estaba yendo y como me pidió que viniera de manera urgente...

\#2: Que asco, pero qué asco...jUsted sabe que me da asco verla así y que el maquillaje es una obligación!

\#1: ii¿¿Quééééééé??! ¿Es? ¿Es tu nana?

\#2: Bueno, pregúntenle rápido y que se vaya.

\#1: Pero, ¿por qué no me dijiste... que era así? ¡Tú, india? ¡Qué me hiciste! Y yo que te toqué... iiTe toqué!!

(Todos se alejan, en grupo, de La Empleada)

14 El personaje es interpretado por las actrices María Elena Valenzuela y Daniela Fernández. 
\#2: No nos haga nada, por favor... te podemos pagar... no nos mates, estamos defendiendo tu raza...

\#1: Sub-raza.

\#4: ¡Cállese! Y no la miren a los ojos...

\#1: Véanle si tiene ramitas de matico en sus bolsillos, quizás nos va a hacer unas magias o unos símbolos... No le crean nada, ellos comen perro... comen perro y yo te toqué...

(Moreno, “Los millonarios” 137)

Que los abogados identifiquen a esta nueva actriz como el mismo personaje con quién interactuaron en la escena anterior, cuando para los espectadores evidentemente se trata de otra interprete, genera en primera instancia risas (carcajadas en las funciones a las que esta autora asistió). Sin embargo, en línea con el objetivo del montaje de querer "instalar discusión entre 'chiste y chiste" (como menciona anteriormente Alexis Moreno), es que la operación escénica de cambiar a la actriz y la virulencia con la que los abogados reaccionan ante esta nueva realidad escénica permite al montaje la construcción de un retrato de la oligarquía chilena como un grupo cuyo discurso de superioridad se ha construido esencialmente sobre los pilares del miedo y la ignorancia. El pánico ante la posibilidad de que la empleada los agreda físicamente evidencia el imaginario del mapuche que ha construido esta elite y la clase trabajadora como seres resentidos, violentos por naturaleza, y que operan como agentes del caos y destrucción, siempre buscando la oportunidad para invadir la propiedad del blanco (similar a la percepción del empleador sobre la empleada doméstica como una ladrona en potencia). Este imaginario se complementa, además, con la asociación de la mujer mapuche como bruja, practicante del oscurantismo (los abogados temen que los hechice) y, por ende, perteneciente a una etnia arcaica en relación con el resto del Chile contemporáneo. La ignorancia frente a la nación mapuche hace imposible a los abogados poder dotar al indígena de matices o considerarlo como un sujeto del siglo XXI, sino que lo concibe como una masa homogénea (todos son violentos/potenciales terroristas, todos son brujos) y rígida (sin desarrollo a lo largo de la historia). El miedo y la ignorancia cumplen un rol instrumental, ya que le permite a la elite instalarse desde el polo opuesto, es decir, como un grupo civilizado, representantes del paradigma moderno 
del orden y el progreso y, por lo tanto, defensores de los pilares culturales e ideológicos en los que se sostiene la patria chilena. En ese sentido, la insistencia de \#2 en que su empleada nunca trabaje sin maquillaje y no revele sus rasgos indígenas se instala como metáfora de los intentos de la elite por invisibilizar la heterogeneidad de subjetividades que históricamente ha existido en el territorio chileno.

\section{Genealogía del poder elitario}

¿Cuál es el sustento en el que La María basa su retrato de la oligarquía chilena a través de los abogados en Los millonarios? Durante la obra, cada escena o episodio es introducido con una proyección del título de la escena y con enunciados provenientes de materiales de archivo de distintas época y fuentes: editorial de diarios, entrevistas, avisos de venta de propiedades, entre otros. Por ejemplo, uno de los segmentos es introducido por las siguientes declaraciones hechas en el diario $E l$ Mercurio en 1859:

Los hombres no nacieron para vivir como animales selváticos, sin provecho del género humano. Y una asociación de bárbaros tan bárbaros como los pampas o los Araucanos no es más que una horda de fieras, que es urgente encadenar o destruir en el interés de la humanidad y el bien de la civilización. (Moreno, "Los millonarios", 115)

Desde su fundación en Valparaíso en 1927, El Mercurio se ha posicionado como un bastión mediático, cultural y político de la clase privilegiada en Chile. Los dueños de la publicación son la familia Edwards quienes, junto a los ya mencionados Matte y Angelini, forman parte del entramado oligárquico chileno ${ }^{15}$. Con una línea editorial ligada desde sus inicios a la derecha y al pensamiento conservador, la publicación ha usado su posición de medio de comunicación masivo en distintos momentos de inflexión de la historia del país para suprimir el surgimiento, expansión y éxito de movimientos políticos, sociales y culturales. Desde su oposición y sabotaje a Salvador Allende y las reformas económicas y sociales del gobierno de la Unidad

15 La familia Edwards es dueña del conglomerado El Mercurio Sociedad Anónima y Periodística. Es también dueña de los diarios Las últimas Noticias, La Segunda, y El Mercurio de Valparaíso (el diario de habla hispana más antiguo del mundo). 
Popular (Hersh 277), hasta la criminalización de los movimientos estudiantiles (Cabalin 635), y activistas mapuche, El Mercurio se constituye como una institución de poder (el cuarto poder) que ha acogido y cultivado la estrecha relación que la elite ha tenido con la historia política de Chile. El discurso de naturaleza racista y exterminadora publicado en El Mercurio se articula en sintonía con la visión -propia del siglo XIX- del indígena como un ser inferior. Para José Bengoa (1995) durante este periodo el indígena, aunque legalmente recibe el estatus de ciudadano, es visto por la sociedad criolla como objeto de dominación y servidumbre:

Surge la visión despreciativa del "indiecito" o "indito" según los decires populares de América. El indio, pobre por naturaleza, sufrido por su condición, considerado inculto y no civilizado por la mirada criollo-europea. El conjunto de ideas discriminatorias se fortalece con las teorías evolucionistas de la época: se los considera "miembros de una cultura inferior" (153).

A pesar de que, tal como menciona Bengoa, estas ideas nacieron a partir de una "matriz teórica, elaborada en el siglo XIX en un contexto evolucionista, racionalista y cientificista" (164) que ya han sido superadas por las distintas disciplinas de las ciencias biológica y sociales, este paradigma continúa siendo "el común denominador cultural de las sociedades que se autovaloran como 'civilizadas"' (165). La perpetuidad en el tiempo de la concepción por parte de la elite del indígena como un ser inferior, inherentemente pobre, y dedicado a la servidumbre es acusada en Los millonarios al incluir archivos provenientes del Chile contemporáneo, como por ejemplo:

Yo he tenido jardineros araucanos y son bien buenos... ("Villalobos insiste")

Esta cita del historiador Sergio Villalobos -y Premio Nacional de Historia (1992) - es parte de una entrevista dada en CNN Chile ("Villalobos insiste"), en donde realizó una serie declaraciones similares, discriminatorias y condescendientes hacia el pueblo mapuche ${ }^{16}$. Sin

16 Entre las declaraciones realizadas están: “A través de cinco siglos (los 'araucanos') no han hecho nada. Se han quedado en la inercia", "Le doy muy poco valor [en relación al aporte cultural del pueblo mapuche]. Creo que ha significado un aporte muy pobre" (Emol "Villalobos insiste"). 
embargo, estas opiniones en ningún caso fueron recibidas con sorpresa. Al contrario, la producción académica del investigador en relación con la apreciación del pueblo mapuche y el valor de su cultura en la historia de Chile ha sido consecuente en la construcción de una visión rígida, anticuada y enraizada en el paradigma evolucionista descrito por Bengoa. El historiador Jorge Pavez Ojeda propone una relación simbiótica entre la producción historiográfica de Villalobos y las capas más altas de Chile, describiendo al historiador como "miembro destacado del bloque liberal-conservador, aquel que se ha constituido para encriptar la historia colonialista del país y gobernar contra los avances democratizadores y descolonizadores" (123). La cita de Villalobos proyectada al comienzo de la escena es luego dicha por el abogado \#1:

\#1: Yo he tenido jardineros araucanos y son bien buenos... Pero bueno, son otros tiempos. Antes te comprabas al líder de la federación gremial de dueños de camiones del sur y listo... Ningún conflicto. (Moreno, "Los millonarios" 114)

Las palabras de \# 1 cuya primera parte ("yo he tenido araucanos jardineros araucanos y son bien buenos") proviene de una fuente real, transita y se expande hacia la ficción para construir un discurso que hace eco de la postura de Pavez Ojeda en relación con el esfuerzo histórico de la oligarquía - a través de sobornos y el marco de impunidad en que se llevan a cabo- por clausurar iniciativas políticas de la comunidad mapuche en la zona del Wallmapu. Al mismo tiempo, Pavez Ojeda sitúa a Villalobos - y su retrato celebratorio de un Chile conservador en lo político y culturalmente homogéneo- en sintonía con las políticas represivas de otros movimientos sociales surgidos en Chile en la última década:

Por eso, la retórica de Villalobos se llena de actualidad, una actualidad vista desde las oficinas de El Mercurio o La Tercera, vista también desde el Palacio de La Moneda, con los ojos de un ministro Hinzpeter o de un senador UDI. Para todos ellos, como para Villalobos, aquellos anarquistas, marxistas o mapuche que no aceptan las reglas del juego oligárquico o neoliberal, que cuestionan el pacto de la elite liberal-conservadora, la Constitución autoritaria de 1980 o la épica de la guerra del Pacífico, son el mayor peligro para los intereses de la elite, y se les perseguirá como "terroristas", "encapuchados" o "violentistas". (Pavez Ojeda 126) 
La inclusión de los dichos de un historiador en la ficción de Los millonarios interroga el alcance del poder de este entramado elitario en su dimensión epistemológica. Gran parte (por no decir todas) las chilenas y chilenos durante el periodo escolar tuvimos que leer los textos de Villalobos como parte del currículo del ramo de Historia de Chile ${ }^{17}$, lo que nos permite trazar una trayectoria de la producción cultural a manos de la elite y su hegemonía epistemológica en las categorías de clasificación que han articulado la historia del país.

La operación dramatúrgica de La María de entrelazar discursos provenientes de archivos históricos y de la contingencia nacional con los discursos de los abogados en la ficción produce una dinámica de interdependencia entre lo público y lo doméstico, y lo macro y micropolítico. A su vez, la exposición de este material histórico provoca que el escenario se devenga en un espacio de desclasificación del archivo, por lo tanto reaccionario a la categoría superior que se les ha dado a las fuentes de historicidad oficial y homogéneas. De manera similar, para la investigadora Patricia Artés (2015), la proyección de material de archivo en escena en el montaje permite:

Que la ficción de la anécdota dramática adquiera una dimensión de realidad no por la verosimilitud de la obra (construcción de la estructura del drama) sino por la irrupción de lo real/político, puesto que provoca que la ficción se convierta en un procedimiento para mirar este problema político real. (155)

La revisión de ideas planteadas por Bengoa (1995) y Pavez Ojeda (2012) sirve para articular no solo un contexto histórico y una revisión crítica de las relaciones de poder entre las comunidades de pueblos originarios y los Estados-nación en Latinoamérica, sino también para trazar una genealogía de poder elitario que, como he argumentado, legitima las ideas políticas y culturales que construyen la visión de mundo cristalizada en los abogados de Los millonarios. Esta genealogía de poder elitario queda en evidencia en la decisión de los abogados de utilizar los discursos proautonomía de pueblo mapuche - que problematizan la concepción de patria chilena como un conjunto culturalmente unitario y responsabilizan al Estado de Chile en su rol represor de derechos terri-

17 Su libro Breve historia de Chile (1983) es lectura obligatoria en las escuelas en Chile. 
toriales y culturales de los pueblos indígenas - como base argumentativa de la defensa de Edwin Calluqueo. Así, en el epílogo de la obra, La Empleada lee parte del discurso de cierre redactado por \#3:

(La Empleada entra luego de liberarse de su encierro. Lee los apuntes de\#3)

La Empleada Mapuche: Defensa final, cierre frente al juez de garantía. La hipocresía de un país. Todos estamos enfermos por la historia. Infectados por mentiras y conveniencias ... Porque la izquierda se acostumbró a una transición en donde los principios se desvanecieron mientras lo que se renovaba era la forma de negociar con el empresariado. Porque la derecha se acostumbró a tener una moral privada golpista y otra pública democrática ... Acá la sangre se ha vertido de manera cobarde a través de engaños del Estado, abusos de la empresa privada e indiferencia del resto del país (Moreno, "Los millonarios" 146)

La agencia que tienen los abogados de poder planificar y ejecutar la operación paradojal de situarse como medio de reproducción del discurso reivindicativo del pueblo mapuche - un discurso con el que no comulgan en absoluto - con el solo fin de ganar el juicio, finalmente encarna las ideas sobre flexibilidad y adaptabilidad expuestas por \#1 en la primera escena de la obra. Tal como evidencian los textos a continuación -el primero es parte del diálogo entre los abogados, y el segundo es material de archivo con una frase de Eduardo Matte proyectada en escena- la obra finalmente sitúa a la oligarquía como un grupo que ha operado desde una dimensión externa al resto de la sociedad chilena y, por lo mismo, de forma impune:

\#2: Seremos nosotros quienes le entreguemos justicia a este pobre ser. \#1: Siempre hemos sido nosotros...

\#4: Siempre seremos nosotros.

\#3: Paradoja, contradicción que seamos nosotros... así es Chile... \#4: ¿Quién más lo va a sacar?

\#1: Esto es tétrico, nosotros no tendríamos que estar defendiendo a ese pobre hombre... Nosotros somos los del otro lado.

\#4: No, nosotros mantenemos el equilibrio del absurdo. Estamos más allá del bien y el mal. Y no llegamos nunca por generación es- 
pontánea... nos llaman, siempre nos llaman. Nos piden que actuemos. (Moreno, "Los millonarios" 133)

"Los dueños de Chile somos nosotros, los dueños del capital y del suelo; lo demás es masa influenciable y vendible. Ella no pesa ni como opinión ni como prestigio" Eduardo Matte, 1892.

El poder elitario, que a través del tiempo ha sido transmitido de generación en generación, protegido por instituciones de poder como el judicial y medios de comunicación, y epistemológicamente legitimado por la academia y otras fuentes de producción cultural, habilita a los abogados para manipular conceptos como verdad, justicia, identidad nacional, y patria con fin de mantener un estatus quo que permita su supervivencia y la de su clase en el tiempo. En ese sentido, podríamos considerar a los abogados como los verdaderos historiadores de Chile en tanto han sido, son y serán operadores del relato y, por lo tanto, de lo real.

A partir de lo anterior resulta pertinente preguntarse acerca de la relación entre el lugar de la trama y la ubicación geográfica y espacio de exhibición del montaje. Tal como concluye Moreno "en todos los siglos de discusión, jamás ha existido una solución contundente, solo subterfugios emocionales, absurdos, que revelan su insustancialidad cada cierto tiempo. Y, por lo mismo, considero que con esta idea la obra puede ser reescrita hasta la saciedad, reemplazando el tema mapuche por el de la discriminación, la educación, la salud, etcétera" (Moreno, “¿Qué es la patria?" 149). Se podría sugerir que las palabras de Moreno se sostienen como argumento legitimador de la compañía por querer abordar temática y escénicamente un conflicto que en apariencia les es ajeno. Sin embargo, al situar el relato en el estudio de unos abogados en Santiago - capital de Chile y epicentro del poder político (ejecutivo) y económico- la obra remueve el conflicto en el Wallmapu de su origen geográfico, resituándolo en su origen político, social y de clase. Esta operación dramatúrgica y por cierto política se completa al estrenar el montaje en el Teatro de la Universidad Católica (Teatro UC) ubicado en la zona oriente de la capital e históricamente asociado a un público de clase media y alta $^{18}$.

18 La Pontificia Universidad Católica de Chile no solo ha sido la institución elegida por miembros de la elite económica del país para la realización de sus estudios supe- 
Los millonarios es un montaje que en última instancia busca desarticular los conceptos de patria y nación, revelando la artificialidad de su consenso semántico. A través de la operación dramatúrgica de irrumpir la acción dramática con la inclusión de material de archivo, el montaje propone un ejercicio de historización del relato ficticio (la trama). Al mismo tiempo, la obra pone en evidencia el fracaso del Estado de Chile para solucionar el conflicto en la zona del Wallmapu. Así, Los millonarios se instala como un claro ejemplo del repertorio de obras que conforman el giro ciudadano por cuanto - en sintonía con los movimiento sociales surgidos en la última década - busca evidenciar la naturaleza elitaria del proyecto moderno que articula la República de Chile y, por lo tanto, desestabilizar la imagen país como una nación cuyos símbolos patrios, instituciones, relatos históricos y democracia nacieron a partir de una dinámica de consenso e igualdad económica, social y cultural.

\section{Referencias bibliográficas}

Artés, Patricia. "El teatro interpelado por el contexto: Los Millonarios de Teatro a La María y la puesta en escena en crisis del contexto". Apuntes de Teatro, no. 140, 2015, pp. 152-160.

Bauman, Zygmunt. Liquid times: Living in an age of uncertainty. Cambridge Polity Press, 2007. Impreso.

Bengoa, José. "Los indígenas y el estado nacional en América Latina". Revista de Antropología, vol. 38, no.2, 1995, pp.151-186. Recuperado de https://www.jstor.org/stable/41616172?refreqi $\mathrm{d}=$ excelsior\%3A59071f5eae771b70dcaca2cc0bf453e8

Bourdieu, Pierre y Jean-Claude Passeron. La reproducción. Elementos para una teoría del sistema de enseñanza. Barcelona, Editorial Laia, 1977. Impreso.

Cabalin, Cristián. "Framing y políticas educacionales: los medios como actores políticos en educación". Estudios sobre el Mensaje Periodístico, no. 19, 2013, pp. 635-647. https://doi.org/10.5209/ rev_ESMP.2013.v19.n2.43463

riores, sino que también — solo superada por la Universidad de los Andes- recibe la mayoría de las donaciones privadas, siendo justamente la Celulosa Arauco del Grupo Angelini el tercer mayor donante (Pauta, “Cómo se reparten..."). 
Carvajal, Fernanda y Camila van Diest. Nomadismos y ensamblajes: compañias teatrales en Chile 1990-2008. Santiago de Chile, Cuarto Propio, 2009. Impreso.

Corporación Nacional Forestal. "DL701 y sus reglamentos". Conaf, s. f. Recuperado de https://www.conaf.cl/nuestros-bosques/ plantaciones-forestales/dl-701-y-sus-reglamentos/

El Mostrador. "Parlamentarios oficialistas toman mal crítica de Boric que apuntaba a que el Congreso representa a una elite de Santiago, machista y de clase alta". País, 3 de marzo de 2016, https://www.elmostrador.cl/noticias/pais/2016/03/03/parlamentarios-oficialistas-toman-mal-critica-de-boric-queapuntaba-a-que-el-congreso-representa-a-una-elite-desantiago-machista-y-de-clase-alta/

Emol. "Villalobos insiste en dichos sobre araucanos". Nacional, 22 de marzo de 2014, https://www.emol.com/noticias/nacion$\mathrm{al} / 2014 / 03 / 22 / 651200 /$ villalobos-insiste-en-dichos-sobrearaucanos.html

Forbes. "AntarChile". Forbes, s. f. Recuperado de https://www.forbes. com/companies/empresas-cmpc/?sh=3c2a3fd51dd8 "Empresas CMPC". Forbes, s. f. Recuperado de https://www. forbes.com/companies/empresas-cmpc/?sh=3c2a3fd51dd8

Foucault, Michel. “Les mailles du pouvoir”. Dits et écrits, 1954-1988, vol. 4. Paris: Gallimard, 1994, pp. 297-315. Impreso.

Garretón, Manuel Antonio. “Transición incompleta y régimen consolidado. Las paradojas de la democratización chilena". Revista de Ciencia Política, vol. 16, 1994, pp. 21-32. Recuperado de http://ojs.uc.cl/index.php/rcp/article/view/6928/6460

González, Camila. "Teatro chileno y política: de macro y micropolíticas hacia un 'Giro Ciudadano'. Ideas desde el Reino Unido: críticas y propuestas para el desarrollo de Chile. Eds. Giovanna Cottin, Marcos González y Camila Mella, 2017, pp. 37-52. Impreso.

"Theatre and democracy in Chile. La Re-sentida's. La imaginación del futuro, or the failure of the utopias". World political theatre and performance: Theories, histories, practices, vol. 2. Eds. Mireia Aragay, Paola Botham y José Ramón Prado-Pérez, London, Brill, 2020, pp. 181-197. Impreso.

Gumucio, Rafael. "Mendigos de utilería". Piensa Chile, 2010. Recuperado de https://piensachile.com/2010/11/28/mendigos-deutilerasa/ 
Hersh, Seymour M. The price of power: Kissinger in the Nixon White House. New York, Summit, 1983. Impreso.

Mayol, Alberto. Autopsia. ¿De qué se murió la elite chilena? Santiago de Chile, Catalonia, 2016. Impreso.

Moreno, Alexis. “Los millonarios". Apuntes de Teatro, no. 140, 2015, pp. 109-147. Recuperado de http://ojs.uc.cl/index.php/RAT/article/view/32359

“¿Qué es la patria?”. Apuntes de Teatro, no. 140, 2015, pp. 148151. Recuperado de http://www.revistaapuntes.uc.cl/index. $\mathrm{php} / \mathrm{RAT} /$ article/view/32361/25029

Pavez Ojeda, Jorge. "Colonialismo chileno, censura fronteriza y ortogramas reaccionarios. Respuesta a Sergio Villalobos Rivera". Cuadernos de Historia, no. 36, 2012, pp. 119-136. Recuperado de https://cuadernosdehistoria.uchile.cl/index.php/ $\mathrm{CDH} /$ article/view/29987/31760

Pauta. "Cómo se reparten las donaciones a las universidades". Pauta, 2019. Recuperado de https://www.pauta.cl/nacional/universidad-andes-puc-concentran-mas-50-por-ciento-donaciones-historicas

Publimetro. "Videos tuiteros rememoran cámara oculta de Piñera como mendigo". Teknik, 18 de noviembre de 2021, https:// www.publimetro.cl/cl/teknik/2011/11/18/video-tuiterosrememoran-camara-oculta-pinera-mendigo.html

Wright Mills, Charles. La elite del poder. México, D. F., Fondo de Cultura Económica, 1957. Impreso. 
